\title{
б EDITOR'S CHOICE \\ Welfare state regimes, unemployment and health: a comparative study of the relationship between unemployment and self-reported health in 23 European countries
}

\author{
C Bambra, ${ }^{1}$ T A Eikemo²
}

\begin{abstract}
- An appendix is published online only at http://jech.bmj. com/content/vol63/issue2

${ }^{1}$ Department of Geography, Durham University, UK; ${ }^{2}$ SINTEF Health Research, Norway, and Department of Sociology and Political Science, Norwegian University of Science and Technology, Norway
\end{abstract}

Correspondence to: Dr C Bambra, Department of Geography, Wolfson Research Institute, Durham University, Queens Campus, Stockton on Tees, TS17 6BH; clare. bambra@durham.ac.uk

Accepted 4 September 2008

\begin{abstract}
Background: The relationship between unemployment and increased risk of morbidity and mortality is well established. However, what is less clear is whether this relationship varies between welfare states with differing levels of social protection for the unemployed.
\end{abstract}

Methods: The first (2002) and second (2004) waves of the representative cross-sectional European Social Survey (37 499 respondents, aged 25-60 years). Employment status was main activity in the last 7 days. Health variables were self-reported limiting long-standing illness (LI) and fair/poor general health (PH). Data are for 23 European countries classified into five welfare state regimes (Scandinavian, Anglo-Saxon, Bismarckian, Southern and Eastern).

Results: In all countries, unemployed people reported higher rates of poor health (LI, PH or both) than those in employment. There were also clear differences by welfare state regime: relative inequalities were largest in the Anglo-Saxon, Bismarckian and Scandinavian regimes. The negative health effect of unemployment was particularly strong for women, especially within the Anglo-Saxon $\left(0 R_{L L} 2.73\right.$ and $\left.O R_{P H} 2.78\right)$ and Scandinavian $\left(O R_{L I} 2.28\right.$ and $\left.O R_{P H} 2.99\right)$ welfare state regimes.

Discussion: The negative relationship between unemployment and health is consistent across Europe but varies by welfare state regime, suggesting that levels of social protection may indeed have a moderating influence. The especially strong negative relationship among women may well be because unemployed women are likely to receive lower than average wage replacement rates. Policy-makers' attention therefore needs to be paid to income maintenance, and especially the extent to which the welfare state is able to support the needs of an increasingly feminised European workforce.

The relationship between unemployment and increased risk of morbidity and mortality is well established..$^{1-8}$ However, what is less clear from the existing literature is whether the relationship between unemployment and health varies by welfare state and, if so, the extent to which this can be explained through reference to the different approaches to social protection (particularly wage replacement rates) taken by different welfare state regimes. In this paper, we examine the extent to which relative health inequalities between unemployed and employed people vary across 23 European countries and by the different approaches to social protection taken by the five
European welfare state regimes (Scandinavian, Anglo-Saxon, Bismarckian, Southern and Eastern).

\section{Unemployment and health}

At the individual level, studies have particularly shown that unemployment is associated with worse mental health, including parasuicide. ${ }^{910}$ It has also been linked to higher rates of all-cause mortality $^{67}$ as well as limiting long-term illness, ${ }^{8}$ and, in some studies, a higher prevalence of risky health behaviours (among young men), including problematic alcohol use and smoking. ${ }^{11}$ At the area level, rates of unemployment, especially when used as indicators of deprivation, correlate with poorer neighbourhood health, ${ }^{12}$ and at the country level increases in the unemployment rate have been associated with increased mortality. ${ }^{13}$ Research has also drawn attention to the contributory role of ill health itself as a factor behind unemployment (direct health selection), ${ }^{5714}$ and the importance of ill health-related worklessness in terms of socioeconomic health inequalities. ${ }^{15}$ Studies from various countries have identified poverty as an important intermediary factor in the relationship between unemployment and health.'

\section{Welfare state regimes}

Welfare provision, in the form of cash benefits and welfare services, is acknowledged as an important mediatory factor in terms of the relationship between labour market position and health. ${ }^{16-19} \mathrm{~A}$ crucial aspect of welfare provision, and one which most differentiates welfare states, is income maintenance (to prevent poverty), ${ }^{18}$ particularly during adverse events such as unemployment, old age or long-term sickness absence.

Welfare state regimes place those welfare states that are the most similar (in terms of political tradition, principles, levels of provision, etc) together, emphasising within-regime coherence and between-regime differences. ${ }^{20}$ There are various competing welfare state regime typologies which emphasise diverse aspects of welfare states such as social expenditure levels, decommodification or political traditions (for an overview see Bambra $\left.{ }^{22}\right) .{ }^{21-24}$ Ferrera's fourfold typology, ${ }^{25}$ which focuses on different dimensions of how social benefits are granted and organised, has been highlighted as one of the most empirically accurate welfare state regime typologies. ${ }^{26-29}$ Ferrera ${ }^{25}$ makes a distinction between the Scandinavian, Anglo-Saxon, Bismarckian and Southern countries (box 1). 
More recently, the Eastern European countries have begun to be considered as a distinctive regime type. ${ }^{2022262930}$

\section{Welfare state regimes and unemployment protection}

Social protection during unemployment varies by welfare state regime. To a large degree this reflects the historical influence of differing political traditions, with those countries experiencing more post-war years of Social Democratic rule providing more generous systems of support. ${ }^{24}$ Table 1 breaks down the various characteristics of social protection during unemployment in the five different welfare state regimes. In essence, there are three inter-relating principles underpinning provision: universalism, social insurance and means-testing. ${ }^{18}$ Systems based on universal provision do not make reference to previous contributions or means-testing and are offered to all citizens as long as specific demographic, social or health criteria are fulfilled. Often flatrate benefits are paid. Under social insurance systems, entitlement to benefits is dependent on previous contributions and in most cases subsequent benefit levels reflect previous earned income. Under means-testing, entitlement is restricted on the basis of income and the (often minimal) financial support is targeted at those in most need, usually after they have exhausted all other means (eg, personal savings or social insurance).$^{31}$

The welfare provision of different regimes is governed by these three principles in varying ways. For example, to differing degrees of generosity, universalism is more prominent within the Scandinavian welfare states (high population coverage) and the Anglo-Saxon regime (fixed benefit rates for all), whereas social insurance is the key component of provision within the Bismarckian, Southern and Eastern European welfare states. Means-testing is more commonly a characteristic of the AngloSaxon welfare states; however, it is also used for social assistance payments in other welfare state regimes. For example, in the UK (Anglo-Saxon) unemployment benefit (contribution-based Job Seekers Allowance) is only payable (for a maximum of 6 months) to those who fulfil the minimum National Insurance contribution requirement within the 2 years before claiming (table 1). Most claimants do not meet this criterion and are therefore reliant on means-tested social assistance benefits, particularly income-based Job Seeker's Allowance and Income Support. ${ }^{32}$ However, this mixed approach is also evident in Sweden, where there is a social insurance-based benefit (Unemployment Insurance Benefit) based on past contributions and which pays a benefit as a proportion of previous wages, as well as a means-tested social assistance scheme (Unemployment Assistance Benefit), which pays a (lower) flat rate. ${ }^{32}$ Similarly, a three-tier system is operated in Germany (Bismarckian): those with a full contribution record receive the full unemployment insurance benefit (Arbeitslosengeld), those with a smaller contribution criteria, receive a means-tested insurance benefit (Arbeitslosenhilfe) whereas those who do not have a sufficient contribution record must rely upon the Sozialhilfe social assistance scheme. ${ }^{32}$

Unemployment protection in each welfare state regime therefore represents a complex mix of these differing principles. However, there are clear differences by welfare state regime, due to the influence of differing political traditions, in terms of how these principles are operationalised, particularly in terms of the generosity of benefits paid to the unemployed (replacement rates), the qualifying period and conditions, duration of benefit payments and the waiting period before entitlement is activated. In each of these regards, the Scandinavian welfare states are generally more generous than the other welfare state regimes (table 1), particularly compared with the Anglo-Saxon and Eastern European regimes.

\section{Welfare state regimes, unemployment protection and health}

Differences in the social protection offered to the unemployed could therefore be an important mediatory factor in the relationship between poverty, unemployment and health. ${ }^{7}$ This could be very important in terms of helping to develop policy interventions, particularly in terms of income maintenance provision, to improve the health of the unemployed, reduce inequalities between those in and out of work, and thereby potentially reduce the influence of labour market status on health. Indeed, a study comparing means-tested and nonmeans-tested unemployment benefits in three countries (UK, Germany, USA) found that among the unemployed, those in receipt of non-means-tested benefits had better health than those in receipt of means-tested benefits. ${ }^{3}$

However, as previous studies of the relationship between unemployment and health have tended to focus either on associations between unemployment and health, ${ }^{7}$ or changes to the employment status of people and their subsequent health, within one country, ${ }^{58}$ or in a very limited number of similar countries, ${ }^{3}$ a full examination of the possibly health protective role of different approaches to social protection has not yet been undertaken. Similarly, although there is an emerging comparative social epidemiology literature that examines differences in health by welfare state regime, ${ }^{17} 1922262829{ }^{35-39}$ there has to date been little analysis by population sub-group. ${ }^{22}$ Therefore, in this study we examine the relationship between unemployment and self-reported health in 23 countries through reference to the different approaches to social protection taken by five different welfare state regimes. Specifically, given the differences in social provision by welfare state regime (as described in box 1 and table 1), we test the following two inter-related hypotheses: (1) that the self-reported health of the unemployed will be worse than the employed in all welfare state regimes, and (2) that the unemployed in those welfare state regimes with higher levels of social protection (the Scandinavian and Bismarckian regimes) will have comparatively better self-reported health than those in the other welfare state regimes (Anglo-Saxon, Southern and Eastern).

\section{METHODS}

\section{Data}

The data source is made up of two independent waves of the European Social Survey (ESS) (merged files from 2002 and 2004), from which we analysed 37499 individuals (aged 25-60 years) from 21 countries (table 2). The two health outcome variables were self-reported limiting long-standing illness and fair/poor general health. The main objective of the ESS is to provide high-quality data over time about changing social attitudes and values in Europe. The data and extensive documentation are freely available for downloading at the Norwegian Social Science Data Services (NSD) web site (www. nsd.uib.no).

We used two indicators of morbidity available in the ESS: self-reported general health and limiting long-standing illness. Self-reported general health was constructed from a variable asking "How is your (physical and mental) health in general?" Eligible responses were "very good", "good", "fair", "bad" and "very bad". We dichotomised the variable into "very good or good" health versus "less than good" health " fair", "bad" and "very bad"). As for limiting long-standing illness, people were 
Box 1 European welfare state regimes (ranked by levels of social protection 1-5, high-low). Adapted from Bambra ${ }^{22}$ and Ekemo and Bambra ${ }^{20}$

\section{Scandinavian}

Characterised by universalism, comparatively generous social transfers, a commitment to full employment and income protection, and a strongly interventionist state. The state is used to promote social equality through a redistributive social security system. Unlike the other welfare state regimes, the Scandinavian regime type promotes an equality of the highest standards, not an equality of minimal needs and it provides highly decommodifying programmes.

\section{Bismarckian}

Distinguished by its "status-differentiating" welfare programmes in which benefits are often earnings related, administered through the employer; and geared towards maintaining existing social patterns. The role of the family is also emphasised and the redistributive impact is minimal. However, the role of the market is marginalised.

\section{Anglo-Saxon}

State provision of welfare is minimal, social protection levels are modest and often attract strict entitlement criteria, and recipients are usually means-tested and stigmatised. In this model, the dominance of the market is encouraged both passively, by guaranteeing only a minimum, and actively, by subsidising private welfare schemes. The Anglo-Saxon welfare state regime thereby minimises the decommodification effects of the welfare state and a stark division exists between those, largely the poor, who rely on state aid and those who are able to afford private provision.

\section{Southern}

The southern welfare states have been described as "rudimentary" because they are characterised by their fragmented system of welfare provision that which consists of diverse income maintenance schemes that range from the meagre to the generous and welfare services, particularly, the health care system, that provide only limited and partial coverage. Reliance on the family and voluntary sector is also a prominent feature.

\section{Eastern}

The formerly Communist countries of East Europe have experienced the demise of the universalism of the Communist welfare state and a shift towards policies associated more with the Anglo-Saxon welfare state regime, notably marketisation and decentralisation. In comparison with the other member states of the European Union, they have limited welfare services.

asked if they were hampered in daily activities in any way by any long-standing illness or disability, infirmity or mental health problem. Eligible responses were "yes a lot", "yes to some extent" and "no". We dichotomised this variable into "yes" (regardless of whether to some extent or a lot) and "no". Unemployment was measured by comparing unemployed (including both those currently looking for a job and those who are not) with people in paid work. The question asked in the survey was "what is your main activity, the last 7 days?" Correlation tests between the reporting of employment status in the ESS largely correspond with the Organisation for Economic Co-operation and Development (OECD) rates from 2003 (table 2, last column). People who were currently under education, permanently sick or disabled, retired, doing community or military service were excluded from the analysis along with those doing housework/looking after children. A weight was applied in all analyses to correct for design effects due to sampling designs in countries where not all individuals in the population have an identical selection probability. All analyses were done for men and women separately.

\section{Analysis}

Relative health inequalities were calculated applying a series of logistic regression analyses, in which unemployment was introduced as an independent variable, controlled for age, with health outcomes as the dependent variables. Prevalence rates and rate differences were calculated additionally, using direct age standardisation. In addition, to test the robustness of the main findings, three sensitivity analyses were performed. First, the between-regime differences in the relationship between unemployment and health were tested separately for men and women using the interaction "employment status* regime" within a multi-level design. Second, one-way analysis of variance was used to examine whether the between-regime differences in health outcomes (overall prevalence, prevalence among unemployed, rate difference and relative inequalities) were greater than the within-regime differences. Finally, additional adjustments were made for between-regime differences in the prevalence of unemployment (by sex and country) and differences between regimes in terms of the socioeconomic status (education and occupational class) of the unemployed were also examined. These analyses are detailed further in the online appendix.

\section{RESULTS}

ORs (along with prevalence rates and rate differences) of ill health are presented in table 3 for men and women within each welfare regime separately (country-specific data are presented in table 1 in the Web-only appendix). All results in this table indicate that unemployed people feel unhealthier than those who report to be employed. This association is significant for all outcomes, with the single exception of men with limiting longstanding illness (OR 1.67) in the Anglo-Saxon welfare regime.

There are also clear differences by welfare state regime. Relative inequalities between employed and unemployed were largest in the Anglo-Saxon (men $\mathrm{OR}_{\mathrm{PH}}$ 2.97, 1.92 to 4.60; women $\mathrm{OR}_{\mathrm{LI}} 2.73,1.50$ to 4.95 and $\mathrm{OR}_{\mathrm{PH}} 2.78,1.63$ to 4.73 ) Bismarckian (men only $\mathrm{OR}_{\mathrm{LI}} 2.21,1.74$ to 2.79 and $\mathrm{OR}_{\mathrm{PH}} 2.72$, 2.21 to 3.35 ) and Scandinavian (women only $\mathrm{OR}_{\mathrm{LI}} 2.28,1.71$ to 3.03 and $\mathrm{OR}_{\mathrm{PH}} 2.99,2.34$ to 4.00$)$ regimes, and smallest in the Southern (men $\mathrm{OR}_{\mathrm{PH}} 1.82,1.35$ to 2.46; women $\mathrm{OR}_{\mathrm{LI}} 1.52$, 1.03 to 2.25 and $O R_{P H} 1.66,1.31$ to 2.11 ) and Eastern (women only $\mathrm{OR}_{\mathrm{LI}} 1.65,1.24$ to 2.10 and $\mathrm{OR}_{\mathrm{PH}} 1.76,1.38$ to 2.25 ) welfare state regimes.

According to the size of rate differences and ORs, it appears that the negative health experiences of being unemployed are particularly strong for women within the Anglo-Saxon $\left(\mathrm{OR}_{\mathrm{LI}} 2.73\right.$ and $\left.\mathrm{OR}_{\mathrm{PH}} 2.78\right)$ and Scandinavian $\left(\mathrm{OR}_{\mathrm{LI}} 2.28\right.$ and $\mathrm{OR}_{\mathrm{PH}}$ 2.99) welfare regime. Although the ORs of men's reporting of limiting long-standing illness do not show a distinct pattern (except from the non-significant results in the Anglo-Saxon regime), the reporting of poor general health within the AngloSaxon regime again demonstrates the largest ORs.

The sensitivity analyses (presented in the online appendix) show that welfare state regimes are strongly related to the association of unemployment and women's health and, in terms of health outcomes, that within-welfare state regime variance is significantly smaller than between-welfare state regime variance for measures of prevalence (but not with regard to rate differences and relative inequalities). The association between 
Table 1 Characteristics of unemployment protection in 23 European countries, ranked by welfare state regime $(2004)^{33} 34$

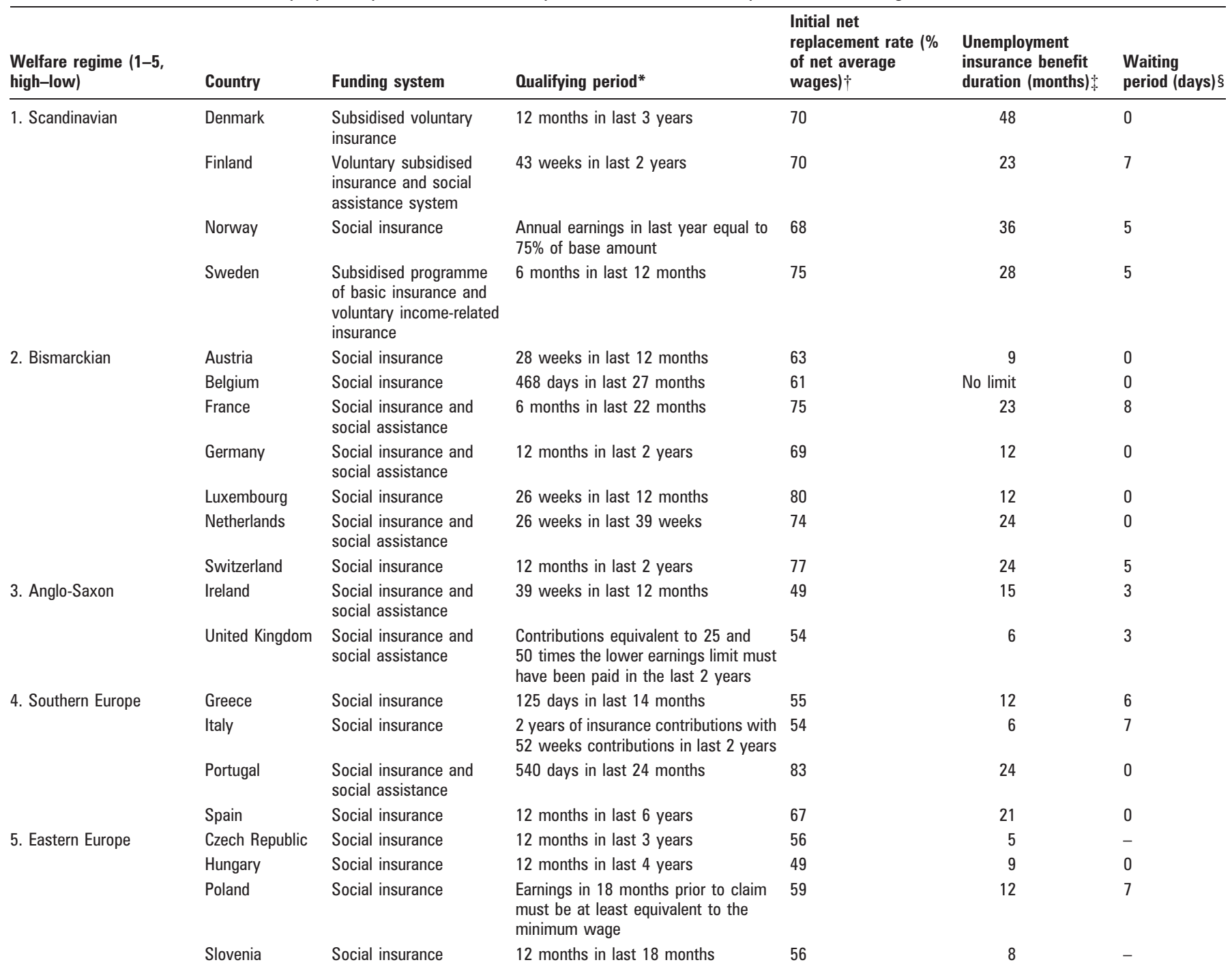

\footnotetext{
${ }^{*}$ For unemployment insurance benefits.

† Net replacement rate $=$ (benefit income when unemployed - tax on benefit income)/(earned income + benefit income when employed - tax on earnings and benefits) $\times 100$; it is assumed that the unemployed worker is 40 years old and has an uninterrupted employment record of 22 years. Benefits included in calculation: unemployment insurance, unemployment assistance, social assistance, family benefits, housing benefits.

\#onths at equivalent to the initial rate for the Czech Republic, the Slovak Republic and Spain, where the benefit level declines overtime (eg, for Spain, where the nominal replacement rate declines from $70 \%$ to $60 \%$ after 6 months, the month's equivalent initial rate is calculated as 6 months plus six-sevenths of 18 months). In most countries after the insurance period ends the unemployed person is entitled to claim social assistance (which may be means-tested).

$\S$ No data available.
}

rate differences and ORs was more evident for women than for men. The additional adjustments made for the prevalence of unemployment confirmed the main findings, that the association between unemployment and health varies by welfare state regime, and in addition, a high correlation as found between the original ORs and the ORs adjusted for the prevalence of unemployment ( $r=0.85$ or higher). This suggests that it is not the higher prevalence of unemployment in some welfare states which has driven the observed differences in the health of the unemployed by welfare state regime. The sensitivity analyses also found that unemployed men and women were more likely to be from the lower socioeconomic groups than employed people in all welfare state regimes.

\section{DISCUSSION}

Our study has found that the relationship between unemployment and health is consistent across all 23 European countries with the unemployed in each country reporting worse selfreported health than the employed (either LI, PH or both). This is in keeping with our first hypothesis and in line with the majority of the existing research literature. ${ }^{5} 7840$ For example, a longitudinal Swedish study found that self-reported physical health decreased with the advent of unemployment and that poorer self-reported physical health increased the likelihood of future unemployment. ${ }^{5}$ Similarly, a longitudinal study of UK men found an increased risk of limiting long-standing illness among the unemployed. ${ }^{8}$ It seems, therefore, that even though the levels of social protection offered to the unemployed vary by welfare state (and welfare state regime), in all countries, a relationship exists between unemployment and poorer selfrated health. This suggests that current wage replacement rates, even in the more generous welfare states, are not sufficient to overcome the financial effects of unemployment on health. On the other hand, it may indicate the importance for health of the non-financial losses associated with unemployment (eg, social 
Table 2 Country statistics

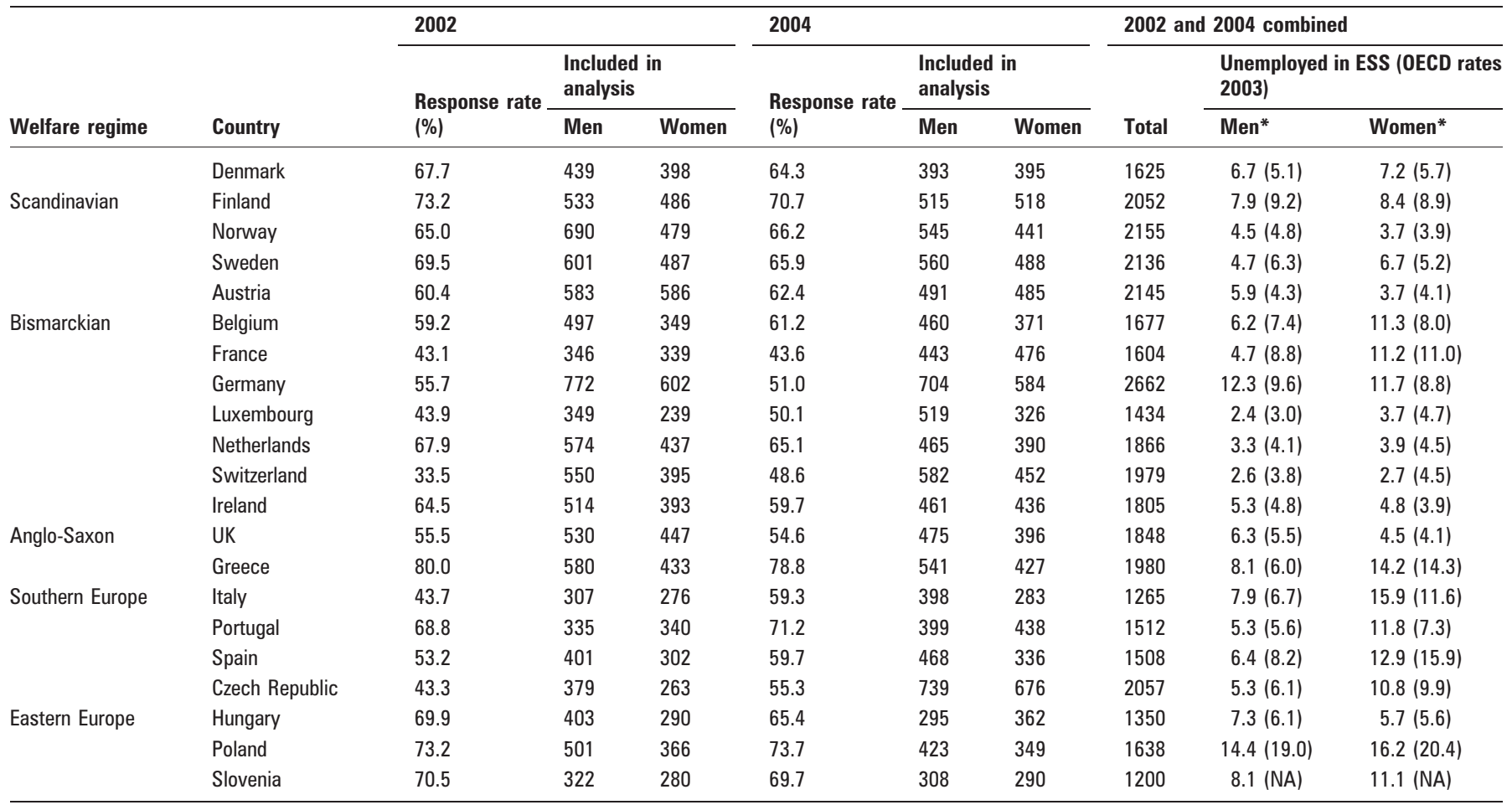

*Correlation between unstandardised European Social Survey (ESS) rates and Organisation for Economic Co-operation and Development (OECD) rates is 0.82 for men and 0.88 for women.

NA, not available.

isolation), as demonstrated in Rudas et al's ${ }^{40}$ study of unemployed Italian workers who despite receiving a 100\% replacement rate still reported elevated levels of physical and mental morbidity. ${ }^{7}$

Although we have found a consistent cross-European relationship between unemployment and poorer self-reported health, we have also identified differences in the magnitude of the relationship by welfare state regime. Specifically, we have found that relative inequalities are largest in the Anglo-Saxon, Bismarckian (men only), and Scandinavian (women only) regimes, and smallest in the Southern and Eastern (women only). The findings for the Anglo-Saxon welfare state regime are perhaps unsurprising given that wage replacement rates for the unemployed are the lowest in these welfare states, and that benefits are means-tested and subject to strict entitlement rules. The unemployed in the Anglo-Saxon welfare states are therefore at a great financial disadvantage in comparison to those in employment and this may well explain the magnitude of inequality as financial strain has been found to be an important factor in the relationship between unemployment and ill health. ${ }^{7142}$ Furthermore, means-tested benefits are associated with stigma ${ }^{18}$ and so the non-financial problems of unemployment may be greater in the Anglo-Saxon welfare states. Our findings are in keeping with broader based studies of welfare state regimes and health indicators which have found that overall population health tends to be worse in the welfare states of the Anglo-Saxon regime. ${ }^{35} 3638394344$

It is harder to explain the findings for the Bismarckian (men only), and Scandinavian (women only) regimes and certainly these are in contradiction to the expectations outlined in our second research hypothesis. Interestingly, unlike the AngloSaxon welfare states they apply only to one or other gender. It is possible that the status differentiating Bismarckian welfare states may tend to exasperate the relationship between

Table 3 Prevalence rates, rate differences and ORs (95\% CI) for each welfare regime separately ( $N=37499)$

\begin{tabular}{|c|c|c|c|c|c|c|c|}
\hline \multirow[b]{2}{*}{ Sex } & \multirow[b]{2}{*}{ Welfare regime } & \multicolumn{3}{|c|}{ Limiting long-standing illness } & \multicolumn{3}{|c|}{ Poor/fair general health } \\
\hline & & Prev (\%) & Unemp (\%) (RD) & OR $(95 \% \mathrm{CI})$ & Prev (\%) & Unemp (\%) (RD) & OR (95\% CI) \\
\hline \multirow[t]{5}{*}{ Men } & Scandinavian & 17.5 & $30.3(13.5)$ & 1.96 (1.47 to 2.61$)$ & 18.4 & $17.6(17.0)$ & $2.27(1.72$ to 3.01$)$ \\
\hline & Bismarckian & 13.7 & $25.1(12.0)$ & 2.21 (1.74 to 2.79$)$ & 20.1 & $19.0(19.8)$ & $2.72(2.21$ to 3.35$)$ \\
\hline & Anglo-Saxon & 11.1 & $16.4(5.7)$ & 1.67 (0.99 to 2.81$)$ & 12.7 & $11.7(16.9)$ & 2.97 (1.92 to 4.60$)$ \\
\hline & Southern & 6.8 & $12.5(6.2)$ & $2.07(1.34$ to 3.18$)$ & 21.9 & $21.2(12.6)$ & $1.82(1.35$ to 2.46$)$ \\
\hline & Eastern & 17.6 & $27.4(10.8)$ & 1.89 (1.43 to 2.52$)$ & 33.1 & $31.6(17.8)$ & 2.15 (1.67 to 2.76$)$ \\
\hline \multirow[t]{5}{*}{ Women } & Scandinavian & 19.4 & $35.3(17.0)$ & $2.28(1.71$ to 3.03$)$ & 17.8 & $35.3(18.7)$ & $2.99(2.34$ to 4.00$)$ \\
\hline & Bismarckian & 14.8 & $23.5(9.4)$ & 1.87 (1.48 to 2.37$)$ & 21.9 & $34.7(13.8)$ & $2.06(1.67$ to 2.55$)$ \\
\hline & Anglo-Saxon & 10.0 & $23.1(13.7)$ & $2.73(1.50$ to 4.95$)$ & 13.6 & $27.5(14.8)$ & $2.78(1.63$ to 4.73$)$ \\
\hline & Southern & 7.8 & $11.8(4.5)$ & 1.52 (1.03 to 2.25$)$ & 30.5 & $39.3(10.1)$ & 1.66 (1.31 to 2.11$)$ \\
\hline & Eastern & 18.1 & $24.4(7.0)$ & 1.65 (1.24 to 2.19$)$ & 38.4 & $49.0(12.0)$ & $1.76(1.38$ to 2.25$)$ \\
\hline
\end{tabular}

\footnotetext{
Prev, total prevalence; Unemp, prevalence among unemployed; RD, rate difference between employed and unemployed.
}

All measures were age-standardised. 
unemployment and poor health by restricting access to the higher level social insurance benefits. The length of entitlement to social insurance is also comparatively low in the Bismarckian welfare states (table 1). That relative inequalities are greater between men than women, may also be in part due to stigma as the familial approach of the Bismarckian welfare states emphasises the male breadwinner role. ${ }^{28} 4546$ In terms of the Scandinavian welfare state regime, the relatively large inequalities between employed and unemployed women may well reflect the fact that women are less likely to meet the qualification criteria for social insurance payments (for example due to higher rates of part-time working) ${ }^{47}$ and are therefore dependent on social assistance benefits which have a lower overall replacement rate. ${ }^{48}$

It is of interest that the smallest relative inequalities between employed and unemployed were found in the Southern and Eastern welfare states. For example, the health differences between unemployed and employed people in the East European welfare regime were never larger than $\mathrm{OR}=2.15$ throughout the study (table 3 ). This is somewhat counter to the wider inequalities in health literature, which suggests that relative inequalities in health by socioeconomic status should be larger in these countries. ${ }^{49} 50$ This finding is therefore very surprising and clearly requires further analysis (perhaps looking at individual countries in these regimes in more depth), not least as the replacement rates and eligibility criteria for the Southern and Eastern welfare state regimes are not particularly generous, holding a fairly moderate position in relation to other regimes (table 1). One possible explanation for the finding is that the more traditional family model in these countries means that additional material, and non-material, support is provided by the family to unemployed members thus buffering the impact of unemployment on health.

Our main results and the sensitivity analyses also suggest that there is an important gender dimension to the relationship between unemployment and poorer self-reported health. Health inequalities between the unemployed and employed were larger among women, most strikingly in the Anglo-Saxon and Scandinavian welfare state regimes. First, this is in contrast to most single country, longitudinal studies, in which the relationship between unemployment and poor health has generally found to be more noticeable among men. Caution should therefore be applied to our findings until they are replicated. However, from a social protection perspective it is less surprising that women experience a more adverse impact on health of unemployment. Women are often not entitled to the higher value social insurance benefits, due to a less coherent employment history, for example, part-time work, periods out of work due to caring etc, and therefore have to rely on lower level social assistance, which provides much lower replacement rates, even in the more generous Scandinavian welfare states. It is also possible that the selection effect is stronger for women than men, that is that unhealthy women are more likely to become unemployed than unhealthy men. Future research clearly needs to explore further the relationship between women, unemployment and health, and the role that the welfare state can play in supporting the needs of an increasingly feminised European workforce.

\section{Limitations}

Although the ESS presents an outstanding opportunity to investigate cross-national patterns of health inequality, as the survey asks the same questions at the same time in all countries, we acknowledge that there are many issues which may affect

\section{What is already known on this subject}

- Single-country studies have shown that unemployment is associated with worse morbidity and mortality.

- Poverty may be an important mediatory factor in this relationship.

- Different types of European welfare state (welfare state regimes) offer different levels of social protection to the unemployed.

- Unemployed people in receipt of means-tested benefits have worse health than those in receipt of entitlement benefits.

\section{What this study adds}

- This study examines whether the relationship between unemployment and health varies by European welfare state regime and, if so, the extent to which this can this be explained through reference to the different types of social protection.

- The negative relationship between unemployment and health is consistent across Europe but varies by welfare state regime, suggesting that levels of social protection may indeed have a moderating influence.

- The negative relationship is particularly strong among women and in those countries with low replacement rates and which utilise means-tested benefits.

\section{Policy implications}

- Unemployment has a negative relationship with health; this may in part be due to the loss of income associated with unemployment. Income levels for the unemployed therefore need to be adequate to prevent health damage.

- Relative health inequalities between the employed and unemployed were greatest in those welfare states that utilised means-tested benefits.

- Welfare state arrangements need to be more sensitive to moderating the effects of unemployment on the health of women, particularly as the European workforce is becoming increasingly feminised.

the comparability of multi-country studies, such as variations in response rate (table 2), modes of data collection, translations, cultural interpretation and conduct. ${ }^{26}{ }^{29}$ Our study is further limited by utilising only self-reported health measures which may vary by country, socioeconomic or employment status and/or culture. For example, an unemployed immigrant living in Spain may use different criteria to define his or her health than an unemployed Finn living in Finland. However, studies have found a strong relationship, which does not vary by socioeconomic status, ${ }^{51}$ between self-reported health and mortality. ${ }^{52}$ Similarly, the measure of unemployment (unemployed in the last 7 days) may obscure important between country differences in the composition of the unemployed population (online appendix). Further, the complex nature of the relationship between unemployment and health means that, despite conducting a number of sensitivity analyses, we 
have not covered all the possible factors influencing between country differences. Another possible limitation is our choice of welfare state regime typology. As noted in the introduction, there is a multitude of competing welfare state regime typologies and no categorisation has yet been generally accepted as the standard typology (although Ferrera's is one of the most accurate in terms of how social benefits are granted and organised). We also carried out a number of sensitivity analyses. However, it must be acknowledged that if the typologies of other authors were used it may have resulted in different results. Finally, as the ESS data is cross-sectional, we cannot rule out selection effects.

\section{Competing interests: None declared.}

\section{REFERENCES}

1. Martikainen P, Valkonen T. Excess mortality of unemployed men and women during a period of rapidly increasing unemployment. Lancet 1996;348:909-12.

2. Martikainen $\mathbf{P}$, Valkonen T. The effects of differential unemployment rate increases of occupation groups on changes in mortality. Am J Public Health 1998;88:1859-61.

3. Rodriguez E. Keeping the unemployed healthy: the effect of means-tested and entitlement benefits in Britain, Germany and the United States. Am J Public Health 2001;91:1403-11.

4. Bartley M. Unemployment and ill health: understanding the relationship. J Epidemiol Community Health 1994;48:333-7.

5. Korpi T. Accumulating disadvantage: Iongitudinal analyses of unemployment and physical health in representative samples of the Swedish population. Eur Sociological Rev 2001;17:255-74.

6. Morris JK, Cook DG, Shaper AG. Loss of employment and mortality. BMJ 1994;308:1135-9.

7. Bartley M, Ferrie J, Montgomery SM. Health and labour market disadvantage: unemployment, non-employment, and job insecurity. In Marmot M, Wilkinson RG, eds. Social determinants of health. Oxford: Oxford University Press, 2006:78-96.

8. Bartley M, Plewis I. Accumulated labour market disadvantage and limiting long-term illness: data from the 1971-1991 ONS longitudinal study. Int J Epidemiol 2002; $31: 336-41$

9. Montgomery SM, Cook DG, Bartley M, et al. Unemployment pre-dates symptoms of depression and anxiety resulting in medical consultation in young men. Int J Epidemiol 1999;28:95-100

10. Platt S. Parasuicide and unemployment. Br J Psychiatry 1986;149:401-5.

11. Montgomery SM, Cook DG, Bartley M, et al. Unemployment, cigarette smoking, alcohol consumption and body weight in young British men. Eur J Public Health 1999;8:21-7

12. Stafford M, McCarthy M. Neighbourhoods, housing and health. In Marmot M, Wilkinson RG, eds. Social determinants of health. Oxford: Oxford University Press, 2006

13. Brenner H. Political economy and health. In Amick B, ed. Society and health. Oxford Oxford University Press, 1995:211-46.

14. Jusot $\mathbf{F}$, Khlat $\mathrm{M}$, Rochereau $\mathrm{T}$. Job loss from poor health, smoking and obesity: a national prospective survey in France. J Epidemiol Community Health 2008;62:332-7.

15. Bambra C. Pope D. What are the effects of anti-discriminatory legislation on socioeconomic inequalities in the employment consequences of ill health and disability? J Epidemiol Community Health 2007:61:421-6.

16. Bartley M, Blane D. Socioeconomic determinants of health: health and the life course: why safety nets matter. BMJ 1997;314:1194-5.

17. Dahl E, Fritzell J, Lahelma $\mathbf{E}$, et al. Welfare state regimes and health inequalities. In Siegrist J, Marmot M, eds. Social inequalities in health. Oxford: Oxford University Press, 2006:193-222

18. Diderichsen F. Impact of income maintenance policies. In Mackenbach J, Bakker M, eds. Reducing inequalities in health: a European perspective. London: Routledge, 2002:53-66.

19. Lahelma E, Arber S. Health inequalities among men and women in contrasting welfare states: Britain and three Nordic countries compared. Eur J Public Health 1994:4:213-26

20. Eikemo TA, Bambra C. The welfare state: a glossary for public health. J Epidemiol Community Health 2008;62:3-6.
21. Bonoli G. Classifying welfare states: A two-dimension approach. J Soc Policy 1997:26:351-72.

22. Bambra C. Going beyond the three worlds of welfare capitalism: regime theory and public health research. J Epidemiol Community Health 2007:61:1098-2.

23. Esping-Andersen G. The three worlds of welfare capitalism. London: Polity, 1990.

24. Navarro V, Shi L. The political context of social inequalities and health. Int J Health Serv 2001;31:1-21

25. Ferrera M. The southern model of welfare in social Europe. J Eur Soc Policy 1996;6:17-37.

26. Eikemo T, Bambra C, Judge $\mathrm{K}$, et al. Welfare state regimes and differences in selfperceived health in Europe: a multi-level analysis. Soc Sci Med 2008;66:2281-95.

27. Bambra C. Sifting the wheat from the chaff: A two-dimensional discriminant analysis of welfare state regime theory. Soc Policy Adm 2007:41:1-28.

28. Bambra C, Pope D, Stanistreet D, et al. Gender, health inequality and welfare state regimes: a cross-national study of twelve European countries. J Epidemiol Community Health doi:10.1136/jech.2007.070292

29. Eikemo TA, Huisman M, Bambra $\mathrm{C}$, et al. Health inequalities according to educational level under different welfare regimes: a comparison of 23 European countries. Sociol Health IIIn 2008:30:565-82.

30. Esping-Andersen G. Social foundations of post-industrial economies. Oxford: Oxford University Press, 1999.

31. Rhodes M. The Welfare State: internal challenges, external constraints. In Rhodes M, Vincent A, eds. Developments in Western European politics. London: Macmillan 1997.

32. Eurostat. Social protection in the EU member states. Luxembourg: Eurostat, 2000.

33. Organisation for Economic Co-operation and Development. Benefits and wages: OECD indicators. Paris: OECD, 2006.

34. International Social Security Association. Social security programmes throughout the world. Geneva: ISSA, 2006.

35. Bambra C. Health status and the worlds of welfare. Soc Policy Society 2006;5:5362.

36. Chung $\mathbf{H}$, Muntaner $\mathbf{C}$. Welfare state matters: A typological multilevel analysis of wealthy countries. Health Policy 2007;80:328-39.

37. Martikainen $\mathbf{P}$, Lahelma $\mathrm{E}$, Marmot $\mathrm{M}$, et al. A comparison of socioeconomic differences in physical functioning and perceived health among male and female employees in Britain, Finland and Japan. Soc Sci Med 2004;59:1287-95.

38. Navarro V, Muntaner C, Borrell C, et al. Politics and health outcomes. Lancet 2006;368:1033-7

39. Raphael D, Bryant T. The welfare state as a determinant of women's health: support for women's quality of life in Canada and four comparison nations. Health Policy 2004;68:63-79

40. Rudas N, Tondo L, Musio A, et al. Unemployment and depression: results of a psychometric evaluation. Minerva Psichiatr 1991;32:205-9.

41. Kessler RC, Turner JB, House JS. Intervening processes in the relationship between unemployment and health. Psychol Med 1987:17:949-61.

42. Jackson P, Warr P. Unemployment and psychological ill-health: the moderating role of duration and age. Psychol Med 1984:14:605-14.

43. Coburn D. Beyond the income inequality hypothesis: class, neo-liberalism, and health inequalities. Soc Sci Med 2004;58:41-56.

44. Conley D, Springer K. Welfare states and infant mortality. AJS 2001:107:768-807.

45. Bambra C. The worlds of welfare: Illusory and gender blind? Soc Policy Society 2004;3:201-12

46. Bambra C. Defamilisation and welfare state regimes: A cluster analysis. Int J Soc Welf 2007:16-326.

47. European Foundation for the Improvement of Living and Working Conditions. Part-time work in Europe 2004 [cited 2008 180808]; http://www.eurofound.europa. eu/ewco/reports/TN0403TR01/TN0403TR01 2.htm (accessed 21 Oct 2008).

48. Saarela J. Replacement rates and labour market behaviour. Socioeconom Plann Sci 2006;40:187-211

49. Leinsalu M, Vagero D, Kunst A. Estonia 1989-2000: enormous increase in mortality differences by education. Int J Epidemiol 2003;32:1081-7.

50. Kunst A, Groenhof F, Anderson 0. Occupational class and ischemic heart disease mortality in the United States and 11 European countries. Am J Public Health 1999;89:47-53.

51. Burstrom B, Fredlund P. Self rated health: Is it as good a predictor of subsequent mortality among adults in lower as well as in higher social classes? J Epidemiol Community Health 2001;55:836-40.

52. Idler EL, Benyamini Y. Self-rated health and mortality: A review of twenty-seven community studies. J Health Soc Behav 1997;38:21-37. 